\title{
Comunicação e cultura organizacional na fronteira: as potencialidades das redes sociais nas empresas ${ }^{1}$
}

\author{
Comunicación y mediación de la cultura organizacional: las \\ potencialidades de las redes sociales en las empresas

\section{Communication and mediation of organizational culture: the potential of social networks in companies}

\author{
Henrique Esper Paiva de Souza ${ }^{2}$ \\ Cristóvão Domingos de Almeida ${ }^{3}$
}

\begin{abstract}
Resumo
O objetivo deste trabalho é apresentar os resultados obtidos a partir da pesquisa realizada no projeto de extensão Comunicação Digital nas Organizações de São Borja. O estudo realizado no desenvolvimento do projeto, visa compreender o cenário atual das empresas localizadas em São Borja, na fronteira oeste do estado do Rio Grande do Sul. Com foco nos usos e apropriações das fanpages do site Facebook. O estudo está fundamentado em mídias sociais, estratégias de comunicação e organização como espaço de fortalecimento das atividades comerciais no município. Com base em pesquisa documental e mapeamento das páginas de 310 empresas entre os anos de 2015 e 2016, destacando pontos positivos e negativos das respectivas instituições e as formas de aproximação com seus públicos. Evidencia-se que as redes sociais podem servir como potencialidade ao desenvolver o empreendimento e nas aproximações com os diferentes públicos.
\end{abstract}

Palavras-Chave: Comunicação Digital, Mídias Sociais, Cultura Organizacional, Estratégias Comunicacionais.

\section{Resumen}

El objetivo de este trabajo es presentar los resultados obtenidos a partir de la investigación realizada en el proyecto de extensión Comunicación Digital en las Organizaciones de São Borja. El estudio realizado en el desarrollo del proyecto, busca comprender el escenario actual de las empresas ubicadas en São Borja, en la frontera oeste del estado de Rio Grande do Sul. Con foco en los usos y apropiaciones de las fanpages del sitio Facebook. El estudio está fundamentado en medios sociales, estrategias de comunicación y organización como espacio de fortalecimiento de las actividades comerciales en el municipio. Con base en investigación documental y mapeo de las páginas de 310 empresas entre los años 2015 y 2016, destacando puntos positivos y negativos de las respectivas instituciones y las formas de acercamiento con sus públicos. Se evidencia que las redes sociales pueden servir como potencialidad al desarrollar el emprendimiento y las aproximaciones con los diferentes públicos.

Palabras claves: Comunicación Digital, Medios Sociales, Cultura Organizacional, Estrategias de comunicación.

\footnotetext{
${ }^{1}$ Trabalho apresentado no II Congresso Internacional Interdisciplinar em Ciências Humanas - COINTER, São Borja/RS, Brasil, 2017.

${ }^{2}$ Graduando em Relações públicas e bolsista AGP do Grupo de Pesquisa Relações de Fronteira: história, política e cultura na tríplice fronteira Brasil, Argentina e Uruguai; Universidade Federal do Pampa (UNIPAMPA); São Borja/ RS, Brasil; henrique.esper@gmail.com.

${ }^{3}$ Pós-doutor e doutor em Comunicação, mestre em Educação, graduado em Relações Públicas e é professor; Universidade Federal do Pampa (UNIPAMPA).
} 


\begin{abstract}
The objective of this work is to present the results obtained from the research carried out in the Digital Communication extension project in the Organizations of São Borja. The study carried out in the development of the project aims to understand the current scenario of the companies located in São Borja, in the western border of the state of Rio Grande do Sul. Focusing on the uses and appropriations of the fanpages of the Facebook site. The study is based on social media, communication strategies and organization as a space to strengthen commercial activities in the municipality. Based on documentary research and mapping the pages of 310 companies between the years 2015 and 2016, highlighting positive and negative points of the respective institutions and ways of approaching their audiences. It is evident that social networks can serve as potentialities in developing the enterprise and in the approaches to the different publics.
\end{abstract}

Keywords: Digital Communication, Social Media, Organizational Culture, Communication Strategies.

\title{
1. Introdução
}

O objetivo deste artigo é apresentar pesquisas realizadas em 2015 e 2016, identificando como as empresas de São Borja usam e se relacionam com seus públicos através de estratégias de comunicação digital, tendo em vista o município localizado na fronteira Oeste do estado do Rio Grande do Sul, interiorano, com 335 anos de história e possui cerca de 60 mil habitantes. $\mathrm{O}$ artigo se apoia no argumento que nos dias atuais as empresas precisam usar e se apropriar das redes sociais, pois a partir desses espaços digitais as organizações conseguem manter diálogo com seus públicos, aproximação e estabelecer processos de fidelização.

Nos últimos anos 20 anos os indivíduos estão adquirindo novos hábitos e formas de raciocínio, com a presença da internet, intensificaram-se esses processos e de modo dinâmico auxiliam a era informatizada para que cada indivíduo tenha de forma democrática acesso às informações disponíveis. Os dispositivos utilizados para acessar a rede mundial de computadores avançaram, e muito, dentre estas variáveis, estão os incentivos por partes dos governos e o valor que era pago para adquirir os equipamentos e custear o manuseio. Esta facilidade no acesso, trouxe consigo novas formas de se comunicar. As organizações se atentaram a esta disponibilidade de acesso e buscam as oportunidades para garantir resultados positivos.

Este estudo traz as questões da comunicação organizacional digital no município de São Borja, com intuito de dar visibilidade às estratégias de comunicação digital das empresas no Facebook e se estão sendo feitas, auxiliando administradores locais, apresentando dados consistentes para reflexão.

A abordagem metodológica deste estudo é de cunho qualitativo. Para coletar as 
informações utilizamos os seguintes instrumentos: levantamento documental dos empreendimentos empresariais da cidade. Identificamos 310 empreendimentos comerciais no município (ACISB, 20154). Realizamos também mapeamento da presença das empresas no Facebook; entrevistas em profundidade com os administradores, para saber se as empresas de São Borja estão inseridas na rede social Facebook. Para realizar o tratamento desses dados, trabalharemos com a análise focada no "grau da conexão de uma rede ego" (RECUERO, 2011, p. 71) que se traduz em: analisar a popularidade de uma página através de suas conexões com seus seguidores, por curtidas, comentários dentre outras interações entre os usuários.

Evidencia-se que as redes sociais podem servir como potencialidade de desenvolver o empreendimento e aproximar os diferentes públicos, quando usadas a partir de estratégias tomadas para melhor desempenho, e, com isso, o surgimento de novas identidades, nova cultura organizacional e resultados satisfatórios às organizações.

\section{Transformações da comunicação digital no ambiente empresarial}

A inserção das redes sociais na internet causa transformações. Essas mudanças estão sendo objetos de estudos de diversos autores ao redor do mundo. Castells (2008) diz que a formação de redes e à flexibilidade: tornam praticamente indistintas as fronteiras de participação e de envolvimento, individualizam as relações sociais de produção e provocam instabilidade estrutural do trabalho, do tempo e do espaço. Essas dimensões também recebem atenção de Santaella (2010) e Terra (2011), como ruptura das variáveis clássicas da comunicação e das bases materiais da vida (CASTELLS, 2008), possibilitando as mensagens serem registradas por longos períodos e a presença em lugares onde não se está físicamente, para além das fronteiras geográficas.

Ao tratar de estratégia e, conectando com a comunicação digital, é importante ressaltar que essas informações, com auxílio da tecnologia e profissionais capacitados, compreendendo e adaptando-se às novas tecnologias vêm para somar a resultados positivos à organização. Castells (2001, p. 8) observou que:

Essas tecnologias permitem a coordenação de tarefas e a administração da complexidade. Isso resulta numa combinação sem precedentes de flexibilidade e desempenho de tarefas, de tomada de decisão coordenada e execução descentralizada, de expressão individualizada e comunicação global, horizontal, que fornece uma forma organizacional superior para ação

\footnotetext{
${ }^{4}$ Associação Comercial Industrial de Prestação de Serviços e Agropecuária de São Borja.
} 
humana.

As tecnologias atualizam-se a cada dia. Dentro das empresas não é diferente, elas precisam estar sempre se reciclando, renovando, necessitam de tecnologias avançadas para conseguirem melhor desempenho e produtividade. Com profissionais qualificados, identificando qual tecnologia é a melhor para exercer a atividade, desta forma, articula com os preceitos elencados por Castells (2001) principalmente no que diz respeito a flexibilização e os trabalhos descentralizados.

A comunicação digital se insere nessas dimensões porque traz diversas opções para as corporações trabalharem diretamente com seus públicos. Dentre elas estão as redes sociais da internet, web sites, televisão, programas radiofônicos, entre outras. Uma das opções mais usadas pelos empreendedores são as redes sociais da internet, vêm sendo usadas por empresas e indivíduos, para auxiliar na divulgação das ações e os empreendimentos, criando uma nova cultura organizacional. Para Schuler (2009) criar uma nova cultura organizacional significa:

Todo processo de mudança organizacional desejado, trazendo novas formas de organização e de administração, implica, essencialmente, um processo de mudança cultural. A intervenção cultural é, basicamente, um processo de comunicação, em que as novas informações e as novas vivências funcionam como força transformadora, que necessita, contudo, de tempo, de sustentação e de perseverança para se manifestar como transformação efetiva. (SCHULER, 2009, p. 269)

Conectando com o pensamento de Kunsch (2009), as redes sociais estão em constante evolução e as organizações devem aproveitar as ferramentas para ampliar seu campo de atuação e obter feedback ${ }^{5}$, divulgação de seus produtos. Desse modo, cada empresa deve utilizar as informações para redimensionar ações ou fortalecer as melhores práticas.

Recuero (2011, p. 102) conceitua redes sociais como "espaços utilizados para a expressão das redes sociais na internet", ou seja, a autora faz a diferenciação entre redes sociais mobilizadas pela sociedade civil e aquelas utilizadas pelas pessoas no mundo digital. Nesse sentido, as redes sociais passaram a ser centrais no relacionamento virtual, usando de sites e outras plataformas.

Desde os primeiros sites de redes sociais, os brasileiros se destacam pela quantidade de usuários inseridos. Com tamanha relevância, as ferramentas geram o seguinte questionamento: como as empresas podem utilizar a comunicação digital e obter resultados satisfatórios?

\footnotetext{
${ }^{5}$ Retorno/resposta de determinada ação praticada pela empresa.
} 
Esta questão vem sendo desmistificada no dia a dia, pois em um país em que $96 \%$ das empresas têm acesso à internet e 36\% das empresas instaladas no país já utilizam as redes sociais digitais (CETIC, 2013) ${ }^{6}$, demonstra que muitos administradores não conseguiriam visualizá-las como uma ferramenta eficaz para seus negócios.

Se, em 2013, mais de 36\% dos administradores brasileiros estão nas redes sociais digitais, entendemos que elas são fundamentais para ampliar seus negócios e promover a interação com os públicos. Essas informações revelam a importância de estarem inseridas nas tecnologias atuais. As empresas ao compreenderem esse fator como relevante na promoção da nova cultura organizacional também podem agir e conquistar resultados, pois, podem passar a ampliar o uso e apropriar com mais intensidade dessas plataformas.

\section{O contexto das empresas de São Borja}

A cidade de São Borja, com mais de 330 anos de história, fundada em 1682, é uma das cidades mais antigas do Brasil. Está a cerca de 600 quilômetros de distância da Capital do estado e faz fronteira com a Argentina, cidade de Santo Tomé. É reconhecida como a Terra dos Presidentes. Pois foi o local de nascimento dos ex-presidentes Getúlio Vargas e João Goulart. Além disso, a cidade é conhecida também pelo seu tradicionalismo regional ainda presente em CTGs (Centro de Tradições Gaúchas), com intensa organização durante a semana farroupilha e, as marcas da tradição são vistos no cotidiano, uma vez que as pessoas usam as vestimentas gauchescas.

De acordo com a Associação Comercial Industrial de Prestação de Serviços e Agropecuária de São Borja (ACISB), no município existem 310 empreendimentos em plena atividade. Interpretaremos a partir das metodologias utilizadas para análise do cenário, compreendendo como estão sendo utilizadas as tecnologias para comunicação digital das empresas para os públicos e os impasses que os administradores locais estão desenvolvendo com a vasta possibilidade de tecnologias comunicacionais disponíveis no mercado.

Tomamos como foco para nosso levantamento os sites de redes sociais. Justificamos a escolha por se tratar de uma plataforma mais acessada pelo público brasileiro, segundo a pesquisa brasileira mídia 2015. O estudo realizado, buscou as redes sociais, Facebook, Whatsapp, Youtube, Instagram, Google+, Twitter, Skype e Linkedin entre outras para evidenciar qual os brasileiros utilizam mais. As três mais usadas foram Facebook (83\%), Whatsapp (58\%) e Youtube (17\%). Com este resultado focamos no Facebook para começar as

\footnotetext{
${ }^{6}$ Centro Regional de Estudos para o Desenvolvimento da Sociedade da Informação (Cetic.br).
} 
indagações sobre o uso da comunicação digital pelas empresas de São Borja.

A partir deste levantamento, selecionamos cinco empresas para realizarmos entrevistas buscando compreender a realidade sobre a inserção delas na rede social digital. Essas informações são relevantes para entendermos como são elaboradas as estratégias de comunicação digital a partir do Facebook, ou, no caso das organizações que não fazem o uso, quais são os motivos para ainda não estarem inseridas.

Após o mapeamento das 310 empresas existentes no município, realizamos buscas nas redes sociais para verificar a existência das empresas no mundo digital, ao mesmo tempo, analisamos cada pesquisa para determinar onde cada empresa se encaixaria: usam ou não. A partir do levantamento foram feitas separações para que pudéssemos identificar três tipos de "uso" feito pelas empresas, o "Perfil", destinado a pessoas físicas que procuram relacionamentos no site, como amizade, namoro, ou seja, qualquer tipo de relacionamento que o site ofereça. Funciona como uma conta principal da página para em seguida criar uma "Página", destinada a agrupar em uma única página todos os usuários que são cadastrados neste site e que buscam informações sobre ela. Isto é, "Página", é o lugar ideal para fazer com que a comunicação digital flua, usando estratégias para trazer resultados positivos para o administrador da página em questão e o último filtro são as empresas que não fizeram um perfil e também não fizeram uma "página".

\section{O uso da comunicação digital: informações coletadas a partir das empresas}

Ao mapear as organizações obtidas a partir do levantamento documental realizado em 2015, pode-se notar que $49 \%$ das empresas não utilizam esta plataforma, $10 \%$ utilizam, mas não tem conhecimento para se inserir a esta plataforma de forma estratégica e $41 \%$ estão inseridas.

Figura 1: Mapeamento 2015 


\section{Das 310 empresas analisadas...}

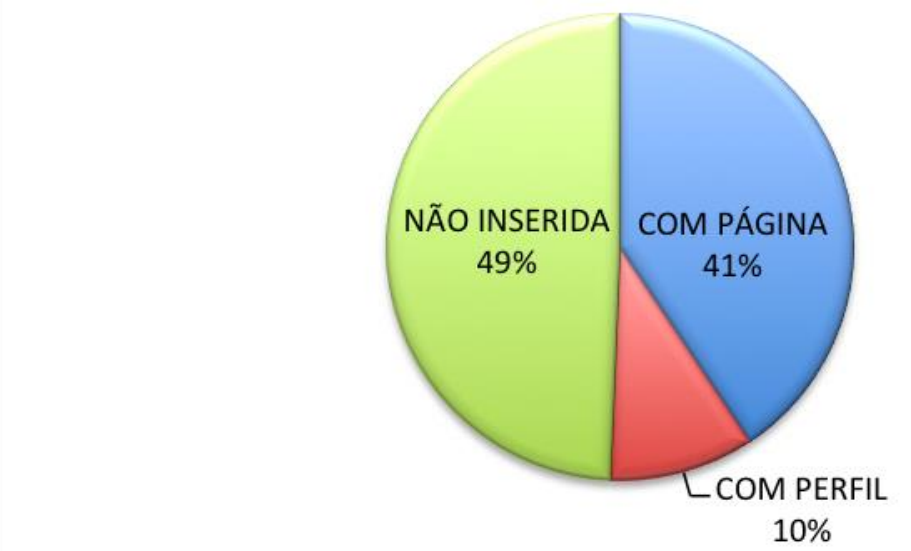

Fonte: Os autores (2015).

Estes dados revelam que grande parte das empresas estão inseridas nas redes sociais, mas esta inserção está ocorrendo de forma lenta, pois as empresas devem usar as novas tecnologias de modo a buscar resultados positivos. Sabe-se que os benefícios das redes sociais para a comunicação digital estão além de criar uma página, mesmo as empresas que estão inseridas no contexto das redes sociais muitas delas não possuem habilidade para o manuseio, menos ainda para o monitoramento dessa mídia, podendo ocorrer distorções nas estratégias e na obtenção de resultados.

Verificamos nas vozes das pessoas que trabalham nos estabelecimentos as necessidades e também os desafios no uso dessas ferramentas. Conforme a resposta do administrador do empreendimento, indica que o propósito é estar inserido, muito embora encontra algumas limitações. Ele diz: "Nós fizemos uma página mas não percebemos nenhum resultado vindo desta página, a partir de um tempo paramos de usar pois, estávamos "perdendo" tempo em cima de uma coisa que não estava nos trazendo resultados para o tempo investido".

O administrador percebe que a empresa precisa estar inserida nas redes sociais, a partir deste momento cria sua conta, mas a deixa em inércia, apenas com os dados da empresa, sem interagir com o público, sem atualizações diárias, isso cria desinteresse tanto dos públicos quanto do gestor.

Este exemplo foi abordado, pois, uma quantia considerável de empresas analisadas se preocupam apenas em entrar na rede, mas não atualizam, não criaram ações, estratégias de comunicação digital, de forma a trazer benefícios para si. Considerando mais frequente o uso 
destas para elaborar técnicas eficazes para atrair resultados, as empresas estão cada vez mais distantes do cenário que está em ascensão quando se trata de redes sociais na internet para aprimorar a comunicação digital na empresa.

Outro administrador, percebe a dificuldade que tem em deixar com que um funcionário monitore a página. Esclarece quando é questionado se a empresa está inserida: “Ainda não, porque nós estamos com um projeto que está sendo posto em prática por uma empresa terceirizada, que cuidará de nossa empresa nas redes sociais, pois nos dias de hoje não podemos mais ficar de fora delas."

Neste outro exemplo, o gestor sabe das dificuldades que para ele seria ao se inserir nas redes fazendo com que um de seus funcionários fique responsável no gerenciamento dessa mídia, mas procura a terceirização para não estar de fora desse contexto.

\section{As práticas exitosas das empresas nas redes sociais}

Os sites de redes sociais são apropriações de usuários através de mediações pelo computador criando "atores" por meio de ações, afim de criar conexões com público alvo, Recuero (2011, p. 30) define o foco do estudo das redes sociais como:

As conexões em uma rede social são constituídas dos laços sociais, que, por sua vez, são formados através da interação social entre os atores. De um certo modo, são as conexões o principal foco do estudo das redes sociais, pois é sua variação que altera as estruturas desse grupo.

Ou seja, são através das conexões que as redes sociais se alteram e se adaptam as mudanças, podendo ser analisada para compreender a dinâmica sem perder o foco das novas tecnologias.

As empresas destacadas como exitosas ou não exitosas, serão analisadas a partir do grau de conexões de suas redes. Para Recuero (2011, p. 71) “quanto maior o grau de conexão, mais popular e mais central é o nó na rede." Ou seja, quanto mais seguidores, curtidas, comentários, compartilhamentos, mais popular é a página. No caso das empresas analisadas, quanto mais popular a página mais visibilidade para a empresa, tratando com êxito a apropriação das redes digitais para a comunicação digital da organização.

Figura 2: Exitosas 


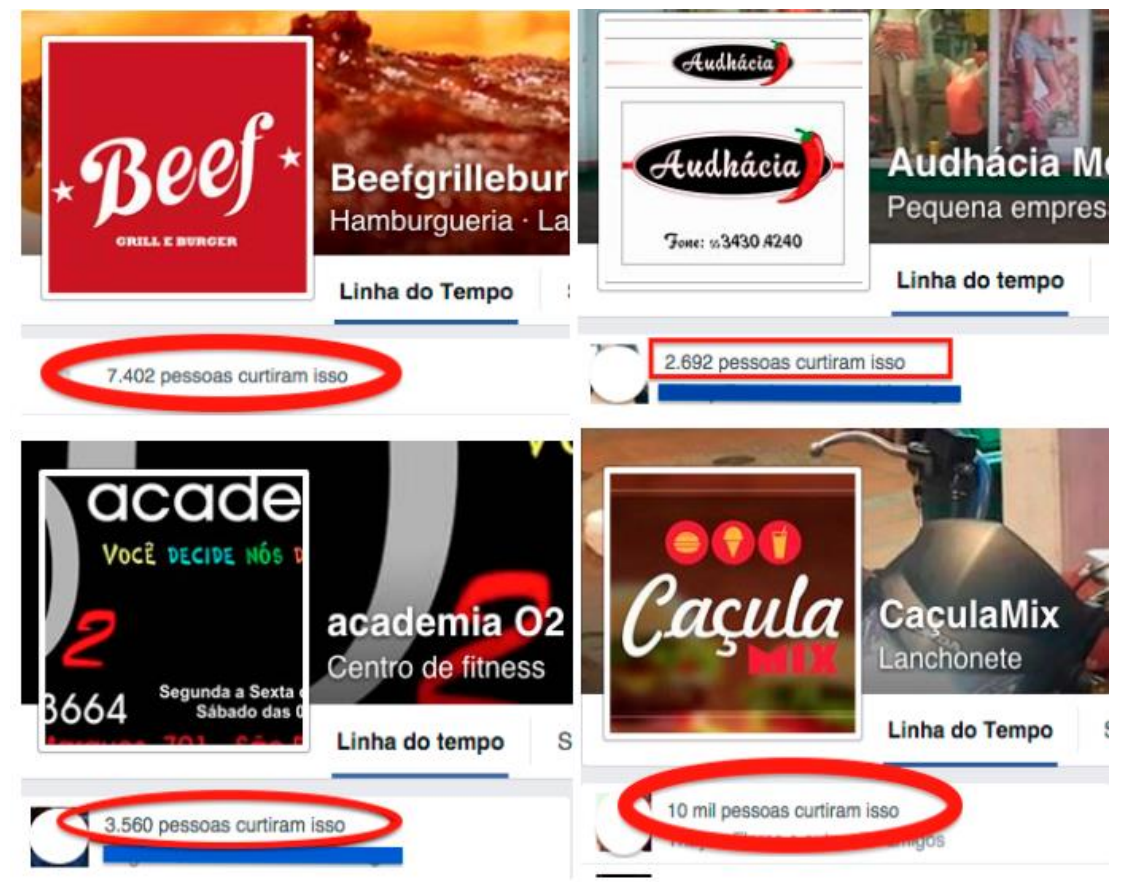

Fonte: facebook.com (2016)

Estas empresas foram classificadas como exitosas pois o número de pessoas que curtiram a página criada por elas foi relativamente alta para o contexto da cidade, criando um elevado grau de conexão, se tornando popular na rede, fazendo com que flua a comunicação digital apropriada pela rede social, dando visibilidade a organização.

Figura 3: Quantidade de curtidas e comentários

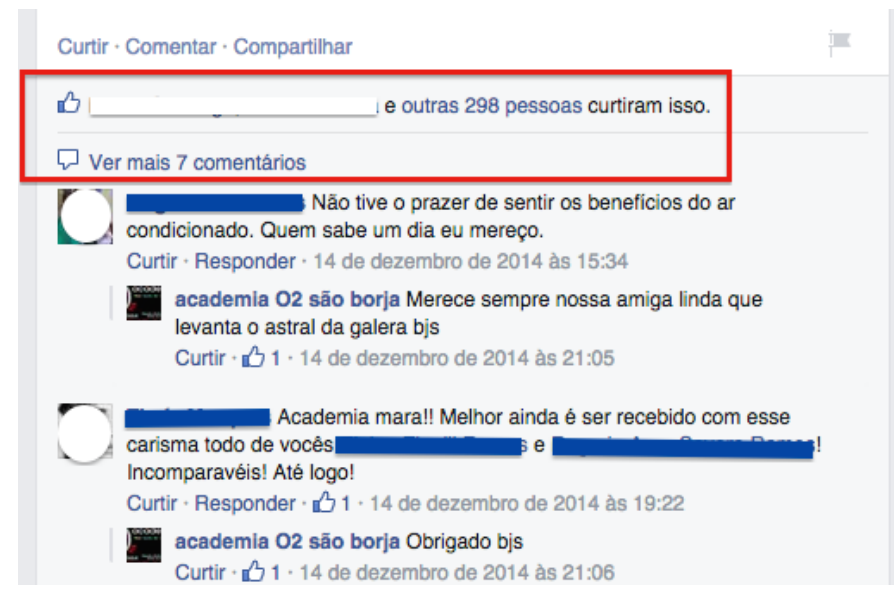

Fonte: facebook.com (2016)

É importante salientar a interatividade para o sucesso nas redes sociais, Recuero (2011, p. 34) afirma que "a interação no ciberespaço também pode ser compreendida como forma de conectar pares de atores e de demonstrar que tipo de relação esses atores possuem.” Ou seja, também determinam o êxito das empresas no sites de redes sociais, pois sabendo utilizar a seu favor, permite estabelecer aproximação com público, fazendo com que haja 
confiança, fidelizando ainda mais o vínculo entre organização e público.

Figura 4: Baixo número de curtidas

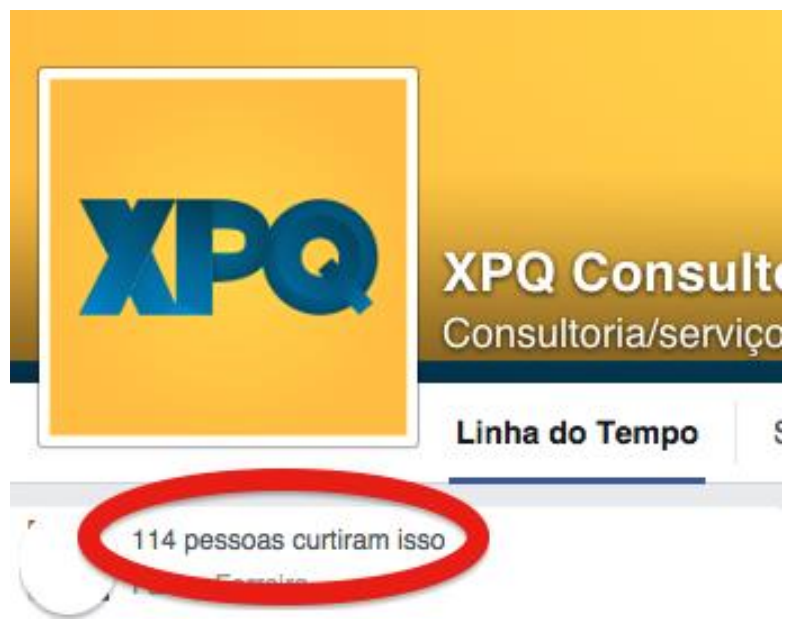

Fonte: facebook.com (2016)

Nota-se o número relativamente baixo de curtidas para o contexto da cidade, não demonstram apenas dígitos, este número baixo, demonstra que a apropriação da rede digital social para aprimorar a comunicação digital não está surtindo efeito. Caso esteja sendo feito algum tipo de investimento, seja ele de tempo ou dinheiro, ainda não obteve retorno.

A mudança de estratégias é necessária para que o administrador não tenha a compreensão de que as redes sociais não se aplicam a sua empresa, pois não conseguem atingir o público, também se faz necessária para trazer resultados positivos e não ser mais um investimento que não obteve retorno, muito pelo contrário, essas novas tecnologias estão disponíveis para auxiliarem a comunicação digital e permitir uma nova cultura organizacional nas empresas.

Figura 5: Perfil
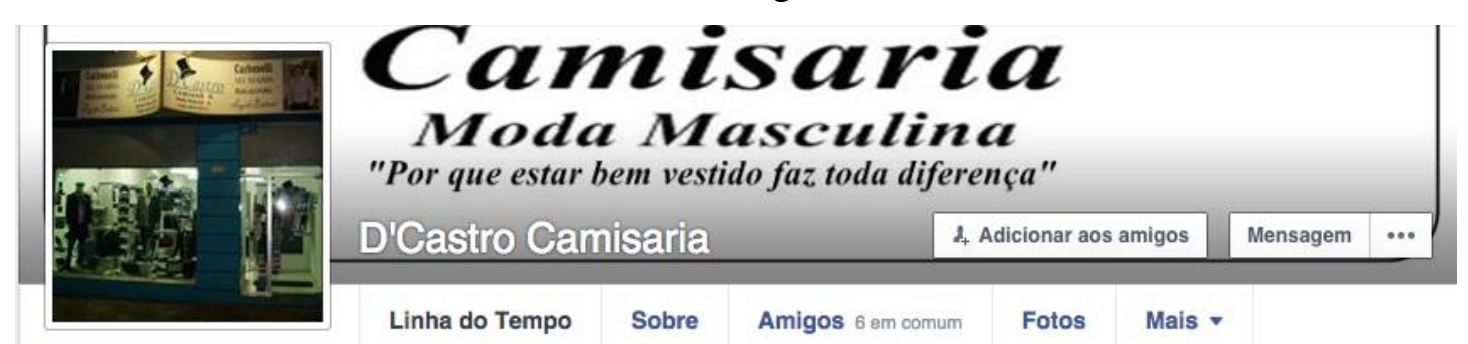

Fonte: facebook.com

Este empreendimento é um dos que fazem parte dos $10 \%$ das empresas que não possuem conhecimento para utilizar o site a seu favor, ao invés de criar uma "página", onde pode ser visto estatísticas de seu uso para obter resultados favoráveis, verificar qual post teve 
mais curtida, quem curtiu a página na semana, ou até mesmo para impulsionar a visibilidade da empresa. Mas, ao contrário disso, foi criado um perfil para a divulgação, expondo a falta de conhecimento no uso dessa plataforma, pois esse modelo dificulta o gerenciamento da mídia.

Diante disso, podemos observar o baixo número de empresas que conseguem atingir o sucesso no uso dos sites de redes sociais na cidade. A falta de conhecimento para a apropriação das redes sociais na comunicação digital, aumenta o número de empresas utilizando de maneira inadequada, desfavorecendo a obtenção de resultados positivos.

Olhando por outro lado, verificamos que as ações diárias das empresas que obtém êxito em suas páginas, fazem o uso com estratégias que favoreçam o posicionamento do empreendimento frente ao seu público. Isto é, conectando interatividade com visibilidade e, cria uma nova cultura organizacional, mudando os hábitos e procurando estar atualizado com as novas tecnologias para oferecer o melhor para seus clientes, buscando estar atento ao mercado.

Com o propósito de identificar as transformações na conjuntura das organizações do município no intervalo de um ano, foi realizado novamente em 2016 o levantamento documental com a ACISB e executado o mapeamento das informações coletadas, os resultados revelam que houve mudanças no contexto das empresas de São Borja no ano de 2016:

\section{Das 295 empresas analisadas...}

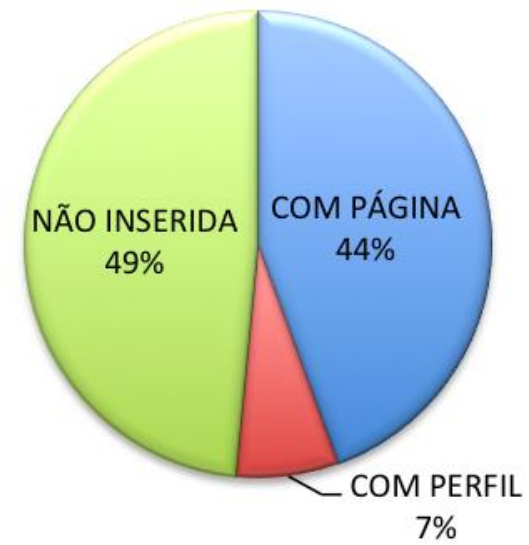

Fonte: Os autores (2016). 
Dentre o intervalo de tempo entre 2015 e 2016, podemos observar mudanças. No gráfico de 2015 foi concluído que: 10\% das empresas que estavam inseridas na plataforma Facebook para se apropriar dela como uma ferramenta da comunicação digital não estavam obtendo êxito, pois não se inseriram como "página", se inseriram como "perfil", não utilizando as ferramentas oferecidas pela plataforma. No ano de 2016 duas mudanças foram notórias: A primeira, queda no número de organizações que utilizam o modo "perfil” de 10\% para $7 \%$. Segunda, se dá pelo aumento de $41 \%$ para $44 \%$ nas empresas inseridas como "página", utilizando as ferramentas oferecidas pela plataforma.

\section{Considerações finais}

Neste trabalho, procuramos mapear, identificar e analisar as empresas do município de São Borja com suas apropriações de novas tecnologias para o uso na comunicação digital. A partir de abordagem qualitativa para notar a eficiência deste novo meio de comunicação frente ao público externo, com mais interatividade e, com o público interno, a partir de uma nova cultura organizacional.

Com os resultados dos mapeamentos em 2015 e 2016 e das análises, podemos observar que muitos administradores dos empreendimentos sabem das dimensões dessas plataformas, mas não possuem conhecimento para se inserir e usar estrategicamente. Algumas empresas ainda permanecem com pensamentos conservadores sobre mudar os hábitos comunicacionais e acabam estagnados ao decidirem não procurar auxílios de novas tecnologias para o seu crescimento.

Portanto, compreende-se que o cenário da comunicação digital nas empresas do município é promissor. Essa condição faz com que os empreendimentos se atentem para as oportunidades que podem surgir através do uso dessas plataformas, especialmente a partir, interatividade e visibilidade dos empreendimentos, isso, por si só justifica o uso dessa mídia como geradora de desenvolvimento e também de uma nova cultura organizacional.

\section{Referências}

BRASIL. Presidência da República. Secretaria de Comunicação Social. Pesquisa brasileira de mídia 2015: hábitos de consumo de mídia pela população brasileira. Brasília: Secom, 2014.

CASTELLS, Manuel. O poder da identidade. São Paulo: Paz e Terra S/A, 2008.

Pesquisa sobre o uso das tecnologias da informação e comunicação no Brasil [livro eletrônico] : TIC domicílios e empresas 2013 = Survey on the use of information and communication technologies in Brazil : ICT households and enterprises 2013/[coordenação executiva e editorial/executive and editorial coordination, Alexandre F. Barbosa ; tradução/translation DB Comunicação]. -- São Paulo : Comitê Gestor da Internet no Brasil, 2014. Acesso em 5 out. 2015. 
RECUERO, Raquel. Redes Sociais na Internet. 2. Ed., Porto Alegre: Sulina, 2011.

SANTAELLA, Lucia e LEMOS, Renata. Redes digitais: a cognição conectiva do Twitter. São Paulo: Paulus, 2010.

SCHULER, Maria. A cultura organizacional como manifestação da multidimensionalidade humana. In. KUNSH, Margarida M. Krohling (Org). Comunicação Organizacional: linguagem, gestão e perspectivas. 2. Ed., São Paulo: Saraiva, 2009.

TERRA, Carolina Frazon. Mídias Sociais... e agora? São Caetano do Sul: Difusão Editora, 2011. 